DE91 011363

\title{
Cross Sections for Actinide Burner Reactors*
}

\author{
Felix C. Difilippo \\ Oak Ridge National Laboratory \\ Oak Ridge, TN 37831-6364
}

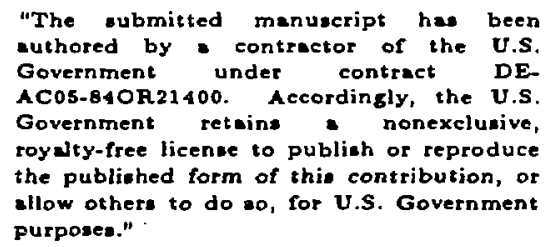

Paper to be submitted to the International Conference on Nuclear Data for Science and Technology, May 13-17, 1991, Julich, Federal Republic of Germany

Send correspondence to:

Felix C. Difilippo

Oak Ridge National Laboratory

P.O. Box 2008

Oak Ridge, TN 37831-6363

* Managed by Martin Marietta Energy Systems, Inc., under contract DE-AC05840R21400, U.S. Department of Energy. 


\author{
Fet:ix C. Difilippo \\ Ont Ridge Nutional Luboratory \\ P.O. Box 2008 \\ Ouk Ridge, TN 3783 1-6363, USA
}

\begin{abstract}
Alustract: Recent studies have slown the fersibility of buming higher actinides (i.e., transuranium (TRL) elements excluding plutonium) in ad hoc designed rebctors (Actinide Burner fReactors: $A B R$ ) whicl, because of their hard neutron spectra, entance the fission of TRL. The iransinutation of long-lived radionuclides into stable or sljort-ljved isotopes reduces considerably the burdun of handling high-level waste from either LWR or Fast Breeder Reactors (FBR) fuels. Because of the large concentrations of higher actinides in these novel reactor designs the Doppler effect due to TRU materials is the most important temperature coefficient from the point of view of reactor safety. Here we report calculations of energy group-averaged capture and fission cross secions us function of temperuture and dilution for higher uctinides in the resolved and unresolved resonance regions. The calculations were done with the codes SAMMY in the resolved region and URR in the unresolved regions and compared with an independent calculation.
\end{abstract}

\section{Introduction}

Neutronic and thermalhydraulic calculations have sliown that it is possible to burn higher actinides in especiblly designed fase reactors which because of their particular hard neutron spectra enhance the fission of transuranic clement (TRU). The analysis of a proposed Actiride Burner Reactor (ABR) plant ( $400 \mathrm{MWe}$ ) shows that it would be possible to burn in one year the amount of reprocessed TRU from eleven 1000 MWe Light Wuter Reactors (L.WIR) that had been operated for one ycar. The transmuta! ion of long-lived radionuclides into stbble or short-lived isolopes reduces considerably the burden of handling high-level waste from either IWR or Fust Breeder Reactors (FBR) fuels.

Detailed calculations of the capture and fission rates are essential to the aforementioned andysis whose accuracy depends on the careful preparation of the cross sections sets. Because of the large concentrations of higlier actinides in these novel reactor designs, the Doppler effect due to TRU materials is the most important temperature coefficient from the point of riew of reactor safety. Here we report calculations of energy group-averaged capture and fission cross sections as function of temperature and dilution for actinides in the resolved and unresolved resonunce regions. The calculations were done with the codes SAMMY? in the resolved region, URR ${ }^{3}$ in the unresolved regions, and the ENDF/B-V evaluation of resonance paramelers (single-level Breit Wigner formalism).

In order to define dilutions of higher actinides in realistic systems we had chosen, as an example, one of the cases analyzed in Ref. 1. Detaila of the unit fuel cell are summarized in Table 1 with information on the TRU isotopic composition.

Table 1. Parameters of a Typical ABR Fuel Cell

\begin{tabular}{|c|c|}
\hline Fuel: & 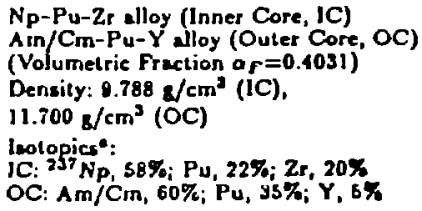 \\
\hline Coolen & $N_{\llcorner}, \alpha_{c}=0.3137$ \\
\hline
\end{tabular}

Fuel Pin Radius: $2 \mathrm{~mm}$

- Weiglit percent.
The dilution of the absorbing atom is parameterized in different ways according to the approximations used to compute the average cross section

$$
\bar{\sigma}_{p, i}(T)=\frac{\int_{E_{i+1}}^{E_{i}} \phi(E) \sigma_{p}(E, T) d E}{\int_{E_{i+1}}^{E_{i}^{i}} \phi(E) d E}
$$

for the process $p$ of the resonant absorber. In the Bondarento treatment $\phi$ is approximated as proportional to $1 / \sum_{1}(E)$ where the tatal cross section $\Sigma_{t}=n\left(\sigma_{t}+\sigma_{0}\right), n$ is the density of the resonant atsorber with total cross section $\sigma_{l}$, and $\sigma_{\theta}$ is the scattering cross section of the rest of the atoms of the mixture per absorbing atom. In other, more accurale, appraximations (like the treatment of the resolved region in the AMPX system) $\phi(E)$ is computed in terms of the scattering cross sections of specific atoms per absorbing atom and their respective masses. Table 2 shows values of $\sigma_{\text {. }}$ for the cell of Table 1 .

Table 2. Scattering Cross Section Per Absorbing Atom for the Cells of Table I

\begin{tabular}{|c|c|c|c|c|}
\hline \multirow[b]{2}{*}{$\begin{array}{c}\text { Abrorbing } \\
\text { Alom }\end{array}$} & \multicolumn{2}{|c|}{$\begin{array}{c}\text { Homogeneous Cell } \\
\sigma_{0} \text { (barn) }\end{array}$} & \multicolumn{2}{|c|}{$\begin{array}{c}\text { IHelerozencou: Cell(c) } \\
\sigma_{*} \text { (barn) }\end{array}$} \\
\hline & All & Sodium & $\begin{array}{l}\text { Isoluted } \\
\text { Lump }\end{array}$ & $\begin{array}{c}\text { Interactive } \\
\text { Lumpo }\end{array}$ \\
\hline${ }^{237} \mathrm{~Np}_{\mathrm{p}}$ & 30.2 & 4.0 & 173.0 & 52.0 \\
\hline $\begin{array}{l}{ }^{241} \mathrm{Am}^{(4)} \\
213 \mathrm{Am} \\
{ }^{213} \mathrm{Cm}^{(b)} \\
214 \mathrm{Cm} \\
{ }^{211} \mathrm{Cm}\end{array}$ & $\begin{array}{r}48.1 \\
178.0 \\
52500.0 \\
295.0 \\
5587.0\end{array}$ & $\begin{array}{r}5.4 \\
11.8 \\
4836.0 \\
28.2 \\
515.0\end{array}$ & $\begin{array}{r}237.0 \\
520.0 \\
210,000.0 \\
1230.0 \\
22000.0\end{array}$ & $\begin{array}{r}71.0 \\
156.0 \\
63300.0 \\
372.0 \\
6800.0\end{array}$ \\
\hline
\end{tabular}

87.63\% Am in Am/Cmalloy; 68.7\% $21 / \mathrm{Am} ; 31.3 \%^{203} \mathrm{Am}$, (from PWR).

O.55\% ${ }^{219} \mathrm{Cm} ; 94.28 \%{ }^{241} \mathrm{Cm} ; 5.17 \%{ }^{243} \mathrm{Cm}$ (from PWR).

cMean chord: 0.1cm; Dane of Coefficient: 0.7. $\%$ denotes the ecape crose section in the Wigner's rational approximation.

\section{Calculations of Cross Section: and Bondarenke Factora}

The codes SAMMY' (for the resolved region) and URR $^{3}$ (for the unresolved region) were used to compute energy group-averaged crose secijons as functions of dilution and temperalure. The Bondarenko approximation for the energy dependence of the flux was used in both regions, so universal parameter $\sigma$. (polential scatlering cross wection of the rest of the mixture of the isotopes per absorbing atom) appeara 


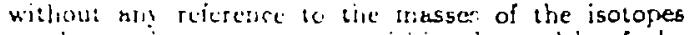
or the moderatorn process within the width of the resolintions.

Yiid) the code SAMASl, we computed the point cross sections as functions of temperature with parameters from the ENDF/B-V e aluation which providus singie-level Brejt- Migncr resonance parameters und ussumes $\mathrm{g}=0.5$ for all resonances. Because SAMMY is based on an R-matrix theory description of the cross sections that requirs the spin of each resonance, wo arbitrarily divided $4 .$. set of resonances into a large munber of spin tarilies in order to eliminate the interference between resonances and $t_{2}$, be consistent with the single-level craluation.

The noxt stcp was to average the temperaturedependent cruss section with the Bondarenko prescription:

$$
\bar{\sigma}_{p, i}\left(\sigma_{o}, T\right)=\frac{\int_{E_{i+1}}^{E_{i}} \sigma_{p}(E, T) w(E, T) d E}{\int_{E_{i+1}}^{E_{i}} t(E, T) d E}
$$

where the weighting function $w$ is

$$
w(E, T)=\frac{1}{\sigma_{\ell}(E, T)+\sigma_{\bullet}}
$$

The Bondarenko factor for process $p$, group $i$, temperature $T$ and dilution $\sigma_{0}$ was also computed according to its definition

$$
B_{p, i}\left(T, \sigma_{0}\right)=\frac{\bar{\sigma}_{p, i}\left(\sigma_{0}, T\right)}{\bar{\sigma}_{p, i}(\infty, T)}
$$

Ne calculated the cross sections in the unresolved rCE' on with the code URR ${ }^{3}$ which computes the probability distribution of the cross section at an input energy while playing Monte Carlo in the surrounding energy region with the average resonance parameters (also from the ENDF/B-V evaluation). After the calculation of the probability table, the cade evaluates the shielded averaged cross sections and the Bondarenko factors. Using the ergadic hypothesis, these parameters are considered average values for the energy region around the input energy; this way of calculating the parameters is faster than the calculation of a ladder of resonances in a broad energy group. The use of ENDF/B-V data allowed us to compare the numerical approach presented here with similar calculations performed with the system of codes AMPX (used by the nuclear industry) which in its present version do not include a R-matrix description of the cross sections. To compare both approaches we select the unresolved region, because it is more important than the resolved region for the design described in Table 1 , and the actinides ${ }^{237} \mathrm{~Np},{ }^{211} \mathrm{Am},{ }^{241} \mathrm{Cm}$, because they are the most slielded of each actinide element.

Figure 1 compares the AMPX results with the URR calculations for infinite diluted capture and fission cross sections of ${ }^{237} \mathrm{~Np},{ }^{241} \mathrm{Am},{ }^{241} \mathrm{Cm}$, in their respective unresolved region: $130 \mathrm{cV}-40 \mathrm{keV} ; 50 \mathrm{eV}-10 \mathrm{keV}$ and $525 \mathrm{eV}-10 \mathrm{keV}$.

The comparison is very good; ${ }^{237} \mathrm{~Np}$ exhibits the structure of tic subthreshold fission so a suitable energy grid would have been necessary to fully describe it which whs nol intended in the calculations of Fig. 1.

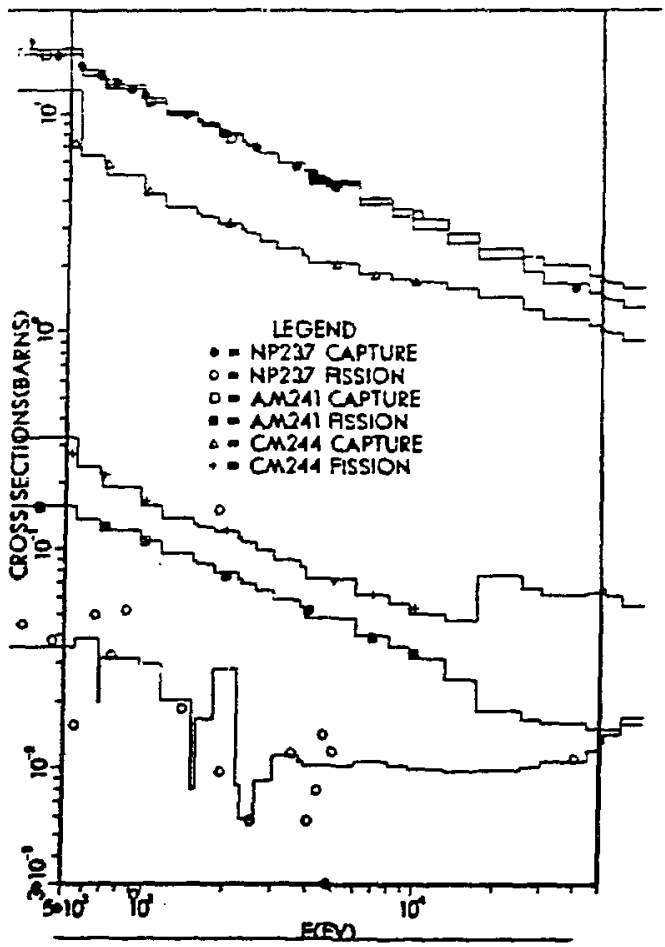

Fig. 1. Infinite diluted actinide cross sections in the unresolved region. Histogram calculated with the AMPX system, points calculated with the URR code.

The Bondarenko factors for the capture process at $T=293^{\circ} \mathrm{K}$ and $\sigma_{0}=100$ barns are shown in Fig. 2 computed with the AMPX system and the URR code. Again the comparison shows consistency.

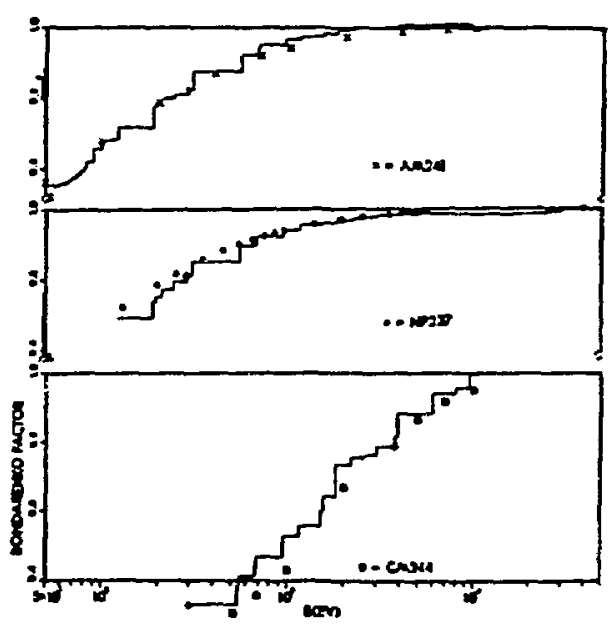

Fig. 2. Bondarenko factor for the caplute process. Histogram calculated with the AMPX system; pointe calculated with the URR code. 


\section{Conclusions}

Because of the mujor presence of higher actinides in ABRs of innorate ciesign ano theit consequent impact on the Doppier coefficient of reaciivity, cfiective capture and fission cross sections and Bondarenko factors were cnlcuiated for ${ }^{237} \mathrm{Ap}$. ${ }^{24} \mathrm{Am},{ }^{243} \mathrm{Am},{ }^{243} \mathrm{Cm},{ }^{244} \mathrm{Cm}$, and ${ }^{243} \mathrm{Cm}$ in the resolved and unresolved resonance regions. The calculations were done with the computer codes SAMMY and URR, which are codes mainly used for the apalysis of experimeatal data. This new approach has the following advantages: (1) It uses the same numerical tool already used in the analysis of experimental data, i.e., the method is more transparent to the original data; (2) improvements in the anajysis of experimental data (e.g., the $R$ matrix analysis periormed by SAMMY) can be introduced directly in the preparation of the cross sections; and $(\dot{3})$ the ergodic hypothesis implemented in the code URR is faster than explicit calculations of ladders of resonances in a broad energy group. Extensive calculations as functions of dilution factors and temperature were made with resonance parameters from ENDF/B-Y (single Breit-Wigner resonance parameters) that allowed direct companson of the results with an independent calculatjon with the AMPX system.

\section{REEERENCES}

1. T. Mukajyamb, H. Trnako, T. Hakizulo, T. Ogawa, Y. Gunjian, and S. Okajims, "Hither Actinides Transmutation Using Higher Actinjdes Burmer Reactors," International Conference on the Physics of Reactors: Operation, Design and Computation, Marseilles, April 1990, Vol. 1, p. 1-97.

2. N. M. Larson, 'Updated Users' Guide for SAMMY: Multileyel R-Matrix Fits to Neutron Dsia Using Bayes' Equations," ORNL/TM-9179/R2 (1989).

3. L. C. Leal, G. deSaussure and R. B. Perez, "URR Computer Code: A Code to Calculate Resonance Neutrons

Section Probability Tables, Bondarenko SelfShielding Factors, and Self-Indication Ratios for Fissile and Fertile Nuclides," ORNL/TM-11297 (1989).

4. N. M. Greene, J. L. Lucius, L. M. Petrie, W. E. Ford, 3 . E. White and $R$ Q. Wright, "AMPX: A Modular Code System for Generating Coupled Multigroup Neutron-Gamma Libraries from ENDF/B," ORNL/TM-3706 (1976). 